\title{
A “Pergunta pela Mulher” nas Ciências Criminais: Contribuições da Metodologia Feminista para O Campo do Direito ${ }^{1}$
}

\author{
The “Woman Question” in CRiminal Sciences: \\ Contributions of a Feminist Methodology to the Field \\ OF LAW
}

\section{La "Pregunta por la Mujer" en Ciencias Penales: Contribuciones de la Metodología Feminista al Campo DEL DERECHO}

\author{
Letícia Cardoso Ferreira* \\ Ana Gabriela Mendes Braga**
}

\begin{abstract}
1 Introdução: um quarto nas Ciências Criminais. 2 Plano de pesquisa e o lugar dessa reflexão. 3 Uma discussão feminista sobre método. 4 Epistemologias para a construção de saberes posicionados no Direito. $5 \mathrm{O}$ método legal feminista proposto por Katharine Bartlett. 6 A universalização da "mulher": categorias de gênero e posicionalidades na metodologia feminista. 7 Arranjos e desarranjos na construção de uma metodologia feminista no sul global. 8 Considerações finais. Referências.
\end{abstract}

\section{RESUMO}

Objetivo: Este trabalho discute as possibilidades e os desafios da aplicação de um método feminista nas Ciências Criminais. Em diálogo com as epistemologias feministas, especialmente mobilizando a noção de saberes posicionados, propomos um exercício de

\footnotetext{
1 Artigo financiado com bolsa Fapesp, no processo n. 2020/04179-9.

* Mestranda no Programa de Pós-Graduação em Direito da UNESP. Graduada em Direito pela USP-RP. Franca - SP - BR. E-mail: <lecardosof9@gmail.com>. https://orcid.org/0000-0002-2591-5894

** Pós-doutora pelo Centro em Rede de Investigação em Antropologia (CRIA - UMinho) e Universidade em Brasília (UnB). Mestra e doutora em Direito Penal e Criminologia pela Universidade de São Paulo (USP), com período sanduíche junto ao Departamento de Antropologia da Universitat de Barcelona (UB). Franca - SP - BR. E-mail: <professora.anagabriela@gmail.com>. https://orcid.org/0000-0001$5291-7580$
} 
A "pergunta pela mulher" nas ciências criminais: Contribuições da metodologia feminista para o campo do direito

estranhamento da representação dos sujeitos criminais nos textos acadêmicos.

Contextualização: As discussões deste artigo são resultado de uma experiência de pesquisa documental centrada nas representações das mulheres que cometem o crime de comércio ilegal de entorpecentes, tendo como fonte artigos científicos publicados em um importante periódico da área. Para destacar as marcas de gênero nesses textos, empregamos o método legal feminista desenvolvido pela autora estadunidense Katharine Bartlett no texto Feminist Legal Methods (1990).

Metodologia: $O$ presente artigo é fruto das reflexões teóricas, políticas e, especialmente, epistemológicas, que surgiram no delineamento metodológico desta pesquisa. Nesse sentido, realizamos, neste artigo, uma revisão da literatura nacional e internacional, especialmente produções feministas sobre métodos e políticas de produção de conhecimento no Direito.

Resultados e contribuições: Com este trabalho, buscamos contribuir para o desenvolvimento de pesquisas na interface de Gênero e Direito, que permitam pensar não só em outros caminhos, mas também em outras perguntas referentes ao campo das Ciências Criminais.

Palavras-chave: Ciências Criminais. Epistemologias feministas. Método legal feminista.

\section{ABSTRACT}

Objective: This paper discusses the possibilities and challenges of applying a feminist method in criminal sciences. In dialogue with feminist epistemologies, especially mobilizing the notion of positioned knowledge, we propose an exercise of strangeness of the representation of criminal subjects in academic texts.

Contextualization: The discussions of this article are the result of a documentary research experience centered on the representations of women who commit the crime of illegal drug trade, having as source of analysis scientific articles published in an important journal in the area. To highlight the gender marks in these texts we use the feminist legal method developed by the American author Katharine Bartlett in the text Feminist Legal Methods (1990).

Methodology: This article is the result of theoretical, political and especially epistemological reflections that emerged in the methodological design of this research. In this sense, we use, in this article, a review of national and international literature, especially feminist productions on methods and policies of knowledge production in law.

Results and contributions: With this work we seek to contribute to the development of research in the interface of gender and law that allow thinking not only of other paths, but also other questions to the field of Criminal Sciences.

Keywords: Criminal Science. Feminist epistemologies. Feminist legal method. 


\section{RESUMEN}

Objetivo: Este artículo analiza las posibilidades y desafíos de aplicar un método feminista en Ciencias Penales. En diálogo con epistemologías feministas, especialmente utilizando la noción de conocimiento posicionado, proponemos un ejercicio de cuestionamiento de la representación de los sujetos criminalizados en los textos académicos.

Contextualización: Las discusiones de este artículo son el resultado de una experiencia de investigación documental centrada en las representaciones de las mujeres que cometen el delito de tráfico ilegal de estupefacientes, teniendo como fuente artículos científicos publicados en una importante revista de la área. Para destacar las marcas de género en estos textos utilizamos el método legal feminista desarrollado por la autora estadounidense Katharine Bartlett en el texto Feminist Legal Methods (1990).

Metodología: Este artículo es el resultado de reflexiones teóricas, políticas y especialmente epistemológicas que surgieron en el diseño metodológico de esta investigación. En este sentido, utilizamos, en este artículo, una revisión de la literatura nacional e internacional, especialmente las producciones feministas sobre métodos y políticas de producción de conocimiento en Derecho.

Resultados y contribuciones: Con este trabajo buscamos contribuir al desarrollo de la investigación en la interfaz de Género y Derecho que permitan pensar no sólo en otros caminos, sino también en otras cuestiones para el campo de las Ciencias Penales.

Palabras clave: Ciencias Penales. Epistemologías feministas. Método legal feminista.

\section{INTRODUÇÃO: UM QUARTO NAS CIÊNCIAS CRIMINAIS}

Em 1928, a escritora inglesa Virginia Woolf proferiu palestras em escolas para mulheres em Cambridge que resultaram no ensaio Room of One's Own ${ }^{2}$ (1929). A imagem-lugar que dá nome ao livro diz sobre as condições de escrita para as mulheres, e, para ela própria, "a mulher precisa ter dinheiro e um teto todo seu, um espaço próprio se quiser escrever ficção" (WOOLF, 2014, p. 12). Além da dimensão geográfica, ocupar um "quarto todo seu" diz da possibilidade de entrar em uma temporalidade própria, descolada da rotina da casa e dos afazeres domésticos, ter também "um tempo todo seu". A autora relaciona as condições materiais com a liberdade intelectual e o direcionamento da força criativa feminina. Além do espaço e do tempo, o quarto com "uma fechadura na porta significa o poder de pensar sobre si mesma" (WOOLF, 2014, p. 50).

A perspectiva da autora parte da experiência de mulheres brancas de classe média no período da Inglaterra vitoriana. Até o fim do século XIX, mesmo com o privilégio da

\footnotetext{
${ }^{2}$ Traduzidos para o português como um Um teto todo seu (2014) e como Um quarto só seu (2019).
} 
A "pergunta pela mulher" nas ciências criminais: Contribuições da metodologia feminista para o campo do direito

raça e classe, as mulheres no Reino Unido não poderiam ter um teto todo seu. A falta do espaço, do tempo e da liberdade - condições que, se presentes, possibilitariam a autoria feminina - atinge também os homens da classe trabalhadora e aponta como esse discurso, à época, operava também em relação à classe: "Porque um gênio como o de Shakespeare não surgia entre pessoas trabalhadoras, sem educação formal, servis. [...] Como, então, poderia surgir entre mulheres, cujo trabalho começava, [...], pouco antes de deixar o berço e ao qual era impelido pelo poder da lei e dos bons costumes" (WOOLF, 2014, p. 73).

Mendes (2020) utiliza a metáfora de Woolf para discutir os espaços da produção acadêmica no Direito Processual Penal no Brasil, apresentando sua própria formulação de "quartos":

[...] o processo penal brasileiro aparece hoje, quase cem anos após a primeira publicação dessa obra magistral (que ocorreu em 1929), como um campo eminentemente masculino estabelecido em quartos bem definidos ideologicamente, tanto em relação ao pensamento alinhado ao poder estabelecido, quanto ao pensamento crítico. Tais quartos são, em verdade loci de homens a afirmarem-se e autorreferenciarem-se (MENDES, 2020, p. 7).

A autora ressalta que as poucas mulheres autorizadas a ocupar esses quartos são as que se comprometem a ratificar essa forma de saber, ou seja, "não tirar a venda que lhes encobre os olhos [...], não trazerem consigo a experiência feminina com o processo [penal] como fundamento epistemológico do que se compreende como conhecimento" (MENDES, 2020, p. 9). Para romper essa lógica, ela aponta a importância da inserção de outros grupos nesse meio, dispostos a trabalhar com novas concepções de ciência.

Partindo da proposição da autora, avançamos para pensar que, mesmo dentro dos grupos marginalizados, outras hierarquias operam na intersecção dos marcadores socais da diferença. As possibilidades de produção do saber e de reconhecimento não se colocam da mesma forma para todas as mulheres. Em 1851, a afro-americana Sojourner Truth proferiu seu famoso discurso ${ }^{3}$, apontando para o lugar específico da mulher negra nas hierarquias de classe e raça na luta pelos direitos das mulheres nos Estados Unidos (DAVIS, 2016, p. 71). Em 1981, a também norte-americana Angela Davis reproduz e contextualiza a fala de Truth: "O fato de sua raça e de sua situação econômica serem diferentes daquelas das demais não anulava sua condição de mulher. E, como mulher negra, sua reivindicação por direitos iguais não era menos legítima do que a das mulheres brancas de classe média” (DAVIS, 2016, p. 73).

No Brasil, Carolina Maria de Jesus publicou, em 1960, Quarto de despejo. O título da obra faz referência não ao cômodo em que a autora habitava, mas à localização da

\footnotetext{
${ }^{3}$ No original Ain't I A Woman?, proferido na Convenção das Mulheres ocorrida em Ohio.
} 
Favela do Canindé na alegoria da autora, da cidade como casa: "Quando estou na cidade tenho a impressão que estou na sala de visita com seus lustres de cristais, seus tapetes de viludos, almofadas de sitim. E quanto estou na favela tenho a impressão que sou um objeto fora de uso, digno de estar num quarto de despejo” (JESUS, 1992, p. 37).

Nessa obra, Carolina narra a forma como era vista pelos demais moradores da favela e por aqueles da "cidade", refletindo sobre o lugar da leitura e escrita na sua vida. Com o sucesso editorial do primeiro livro, Carolina sai da favela para uma "casasobrado, com sala, salinha, quarto, quarto, cozinha, quintal, jardim” (JESUS, 1961, p. 5). Lá escreve Casa de Alvenaria, cujo subtítulo "diário de uma ex-favelada" marca a mudança da localidade da escritora na arquitetura da cidade e do poder: "Agora eu estou na sala de visita. O lugar que eu ambicionava viver. Vamos ver como é que vai ser a minha vida aqui na sala de visita" (JESUS, 1961, p. 47).

Apesar de seu reconhecimento como escritora e sua ascensão social, seu corpo negro é estranhado na sala de visitas. Quase 30 anos após sua morte, Benjamin Moser, em biografia de Clarice Lispector, contemporânea de Carolina, relata ${ }^{4}$ o encontro das duas:

Numa foto, ela aparece em pé, ao lado de Carolina Maria de Jesus, negra que escreveu um angustiante livro de memórias da pobreza brasileira, Quarto de despejo, uma das revelações literárias de 1960. Ao lado da proverbialmente linda Clarice [...] Carolina parece tensa e fora do lugar, como se alguém tivesse arrastado a empregada doméstica de Clarice para dentro do quadro (MOSER, 2009, p. 22).

As narrativas de Quarto de despejo e a descrição imagética da autora pela "elite intelectual" mostram as constantes tentativas de silenciar Carolina. A lógica do despejo, forma como Silva (2019) denomina a violência presente nas relações que ela viveu e descreveu, foi um obstáculo constante para que sua voz ressoasse "livre dos preconceitos que pesavam sobre ela: 'negra, pobre, mulher'” (SILVA, 2019, p. 2). Entretanto, Carolina demonstra em seus escritos a crença no poder transformador da palavra, enquanto forma de denúncia, de luta social e de agência sobre a lógica perversa que nega sua subjetivação (SILVA, 2019, p. 9). Carolina saiu da favela, seu lugar de destino, e ocupou o quadro.

A disputa da possibilidade de falar sobre si mesmo e, logo, de constituir-se enquanto indivíduo e coletivo também está presente no anúncio de Lélia Gonzalez:

[...] nós negros estamos na lata de lixo da sociedade brasileira, pois assim o determina a lógica da dominação [...] por que o negro é isso que a lógica da

\footnotetext{
${ }^{4}$ Após a polêmica em torno da representação do historiador norte-americano, no relançamento da obra por outra editora, o trecho em questão foi alterado. Ver Moser (2017).
} 
A "pergunta pela mulher" nas ciências criminais: Contribuições da metodologia feminista para o campo do direito

dominação tenta (e consegue muitas vezes, nós o sabemos) domesticar? [...] Exatamente porque temos sido falados, infantilizados [...], que neste trabalho assumimos nossa própria fala. Ou seja, o lixo vai falar, e numa boa (GONZALEZ, 1984, p. 225).

As representações dos diversos espaços reservados e ocupados pelas mulheres que reunimos aqui - o quarto todo seu, o quarto de despejo, a sala de estar, a casa de alvenaria, quartos do processo penal - apontam para a complexidade de pensar possibilidades de enunciação do saber frente à diversidade de experiência das mulheres, assim como desestabilizam a generalidade e o alcance da categoria mulher na perspectiva feminista. Essas autoras, nos mais diferentes contextos, pensaram e escreveram sobre os espaços de produção e reprodução dos saberes, bem como sua localização neles. O quarto, a sala de estar ou o lixo nessas narrativas é lugar de emanação do discurso, cenário que produz e é produzido pelas hierarquias da constituição do saber.

Mobilizar o acúmulo da tradição feminista nesse campo nos ajuda na elaboração da arquitetura do conhecimento criminológico e nos dá pistas de como podemos desestabilizar as Ciências Criminais ao agregar métodos feministas à pesquisa em Direito, provocando o lugar de marginalidade do gênero e das perspectivas feministas nesse campo. Esse projeto de desconstrução e reconstrução no campo científico e social se estende, de forma geral, ao longo da história ocidental. A produção de hierarquias de saber tem sido questionada nos marcos do feminismo contemporâneo (HARDING, 1987; HARAWAY, 1995; SMART, 1989; SEVERI, 2017), em especial nas suas perspectivas negras (COLLINS, 2000) e decoloniais (GONZALEZ, 1988; LUGONES, 2008; CURIEL, 2020; MIÑOSO, 2020). Partiremos dessa literatura para pensar e problematizar a constituição da "mulher criminosa" tanto na formulação quanto na análise a ser realizada em nosso trabalho.

\section{PLANO DA PESQUISA E O LUGAR DESTA REFLEXÃO}

A pesquisa que dá origem a este artigo analisa as representações da criminalidade feminina na produção acadêmica nas Ciências Criminais, por meio da aplicação do método legal feminista apresentado pela estadunidense Bartlett (1990). Partimos da categoria Ciências Criminais para tratar de estudos que se inserem no campo acadêmico, partilhando de suas disputas e tensões, sem se afastarem do Direito Penal e Processual Penal e do campo de poder do Direito, mas que também propõem repensar esses saberes a partir de perspectivas mais críticas. Situam-se, portanto, no cruzamento entre dogmáticas e ideias como as das epistemologias feministas.

A escolha da proposta de Bartlett como método visa a disputar formas de olhar e dizer nas Ciências Criminais e no estudo da criminalização. Entretanto, seu emprego demanda indagações e desconstruções, além de trazer desafios na formulação 
metodológica da pesquisa. Nosso objetivo, neste trabalho, é analisar com profundidade esse método, entender como ele se insere nas críticas provocadas pelas epistemologias feministas aos saberes e fazeres do Direito e quais são os obstáculos encontrados para sua aplicação nas Ciências Criminais no país.

Observar a forma de produção científica no Direito em relação às Ciências Criminais é relevante e, ao mesmo tempo, desafiador. Questionar as produções desse saber em torno do crime envolve provocá-lo epistemologicamente e duvidar de suas verdades, algo pouco comum durante a formação jurídica, voltada para o uso de técnicas de aplicação de normas e replicação de teorias atemporais, internalizadas a partir de manuais. Desse modo, não incita a pensar sobre as origens daquele conhecimento, quem o produz, para quem se dirige ou se existem outras formas de conhecimento que não aquelas postas.

Suscitar esses questionamentos possibilita compreender os limites do direito positivado em dar conta da realidade e ser instrumento de transformação social. Também nos ajuda a pensar sobre as configurações entre sujeito e objeto de conhecimento que ele produz. Acionamos essas questões como ponto de partida para desnaturalizar o campo das Ciências Criminais a partir da construção de saberes situados, que levam em consideração outras experiências, vozes e realidades.

Dentro de um projeto epistemológico feminista para o Direito, Bartlett (1990) propõe, em Feminist Legal Methods, a análise das produções jurídicas (textos normativos, decisões judiciais, textos acadêmicos), sob uma ótica distinta da tradicionalmente adotada, centralizada nos sujeitos à margem dos espaços de poder. Ao fazer "perguntas sobre a mulher", Bartlett adota um método posicional, que compreende que o saber universal é sempre excludente. Entretanto, sua aplicação deve ser cuidadosa, a fim de evitar análises essencialistas ou baseadas em estereótipos de gênero e, dessa forma, reificar o universalismo que buscamos questionar.

Assim, além da inserção de produções feministas nas Ciências Criminais, propomos incluir o pensamento negro e decolonial nas criminologias feministas, já que o campo feminista, muitas vezes, utiliza-se das mesmas formas tradicionais de validação do conhecimento e de separação dos saberes legítimos que estamos questionando, fazendo o que a filósofa dominicana Miñoso (2020, p. 98) chamou de "colonialidade da razão feminista”.

Partindo dessas provocações, estruturamos o texto nas seguintes seções. Recorremos à ideia de quartos apresentada na introdução como imagem, buscando conduzir as leitoras a entender como as discussões feministas se inserem e mobilizam os espaços do Direito e das Ciências Criminais em nosso país. Na seção seguinte, questionamos as potencialidades e os limites de um método feminista por meio da teoria de Sandra Harding $(1987,1998)$. Logo em seguida, expomos as principais críticas 
A "pergunta pela mulher" nas ciências criminais: Contribuições da metodologia feminista para o campo do direito

desenvolvidas a respeito dos saberes do Direito, utilizando como referências a teórica britânica Smart (1989) e a brasileira Severi (2017).

$\mathrm{Na}$ quarta seção, abordamos com mais profundidade o método de Bartlett, as razões que inspiraram a autora em seu desenvolvimento e seus três eixos de análise. A seguir, discutimos algumas das problemáticas da estruturação desta pesquisa e de seu transporte para a realidade do sul global. A partir dessas questões, refletimos como articular a categoria mulheres, trazida pela autora, com gênero, raça, classe e outros marcadores sociais. Além disso, buscamos repensar nossas posicionalidades enquanto pesquisadoras e ocupantes desse espaço. Ao final, concluímos que pensar as Ciências Criminais desde uma perspectiva feminista envolve o reconhecimento das marcas do nosso saber e de nossos privilégios, bem como da realidade que analisamos. Propomos que essa realidade não seja apenas um campo a ser explorado pelos detentores do podersaber do Direito, mas sim parte estruturante daquilo que reconhecemos como Ciência Criminal.

\section{UMA DISCUSSÃO FEMINISTA SOBRE MÉTODO}

Sandra Harding, filósofa estadunidense, foi uma das precursoras dos estudos sobre a crítica feminista à ciência. Indagou, desde a década de 1980, sobre os lugares de produção da ciência, especialmente das Ciências Sociais da época, evidenciando a exclusão das mulheres desses espaços. Ao questionar a ciência tradicional ${ }^{5}$, buscou nossos lugares nos espaços acadêmicos e nas disputas de poder que são parte do fazer científico.

Foi também uma autora eloquente na tentativa de responder à pergunta sobre a existência de métodos feministas. Para isso, ela parte da teoria do ponto de vista feminista (feminist standpoint) e dos conceitos de método, metodologia e epistemologia que, em seu entender, possuem diferenças sensíveis, apesar do diálogo inevitável entre eles.

Para ela, método de investigação é uma técnica para coletar e compilar informações, em que são exemplos a escuta dos informantes, a observação de comportamentos, o exame de registros históricos. Já metodologia seria entendida como uma teoria dos procedimentos que a investigação segue - ou deveria seguir - assim como um modo de análise dos resultados desta. Por último, epistemologia seria uma teoria do conhecimento, que teria como escopo responder a perguntas como quem pode

\footnotetext{
${ }^{5}$ Utilizamos as expressões ciência tradicional e ciência moderna no sentido apresentado por Bandeira (2008, p. 212-214), que atribui seu desenvolvimento a pensadores como Bacon e Descartes, e como características o seu alicerce à objetividade e à atemporalidade; é a ciência pensada a partir da natureza ou biologia que rejeita a relação entre o pesquisasor e o fenômeno estudado.
} 
ser o sujeito do conhecimento e o que pode ser considerado como tal (HARDING, 1987, p. 11-13).

Utilizando desses conceitos, a autora afirma, em um primeiro momento, que, apesar das importantes contribuições metodológicas da teoria feminista, elas não poderiam ser caracterizadas como novos métodos feministas de investigação (HARDING, 1987, p. 11). Em sua concepção, recursos utilizados pelos estudos feministas na construção de conhecimento não seriam, na verdade, métodos. Propostas como o enfoque nas experiências das mulheres e a consideração da investigadora no mesmo plano de análise da investigada poderiam ser consideradas características metodológicas ou epistemológicas, uma vez que apontariam caminhos para a aplicação da teoria científica e para diferentes teorias sobre o conhecimento, em oposição àquelas tradicionais (HARDING, 1987, p. 26).

Entretanto, em um segundo momento, Harding, ainda mantendo suas concepções acerca dos termos assinalados, mas observando a evolução no pensamento feminista, muda seu posicionamento. No epílogo do texto Is there a feminist method? (HARDING, 1998, p. 32-34) a autora observa que, no desenvolvimento de sua teoria do ponto de vista e na observação dos trabalhos epistemológicos de feministas de sua época, ela não havia imaginado a possibilidade de utilização do que ela chamou de “características metodológicas e epistemológicas" como métodos de investigação:

[...] essa teoria foi interpretada de forma valiosa como um método de pesquisa no sentido de que responde à questão de como as feministas devem conduzir pesquisas. Esta teoria diz: parta da vida das mulheres para identificar em que condições, nas relações naturais e sociais, é necessária investigação e o que pode ser útil (para as mulheres) que se questione nessas situações. [...] Assim, embora essa forma de produção de conhecimento não seja normalmente o que as pessoas que pensam em 'métodos' de pesquisa têm em mente, seria razoável argumentar que existe um 'método' específico produzido pelos feminismos (HARDING, 1998, p. 33, tradução nossa).

A partir dessas perspectivas, mobilizamos o método feminista como um instrumento interessante para interpretar e enquadrar nosso campo de pesquisa. Consideramos, para isso, não só aquilo que Harding aborda como método em sentido estrito, mas todas as características metodológicas que com ele dialogam e, em última instância, também o compõem. Assim, compreendem aquilo que nomearemos aqui como método ou metodologia feminista elementos como a abordagem posicionada, a consideração dos pontos de vista das investigadoras, o enfoque nas experiências e o uso de estratégias de pesquisa específicas, como a pesquisa empírica.

No Direito, a utilização de métodos inovadores tem o condão de revelar problemas nas concepções tradicionais, bem como diferentes formas de pensá-lo. As escolhas metodológicas da pesquisa revelam o caminho seguido na construção do saber, 
A "pergunta pela mulher" nas ciências criminais: Contribuições da metodologia feminista para o campo do direito

as escolhas político-ideológicas de quem nela trabalha. No entanto, estas têm sido, em muitas produções tradicionais ocidentais, ocultadas ou consideradas desinteressantes para as respostas obtidas (CHANTER, 2011, p. 95). Daí a importância não só dos dados produzidos, mas também a compreensão de que eles só são possíveis, pois partimos de “algum lugar". Método e metodologia são sedimentados desde lugares de onde se parte e corpos que veem e escrevem, e por isso são estruturais para pensar os arranjos e as geografias da produção de saberes.

\section{EPISTEMOLOGIAS PARA CONSTRUÇÃO DE SABERES POSICIONADOS NO DIREITO}

Na seção anterior, discutimos a possibilidade de falar sobre métodos feministas por meio das contribuições de Harding. Nesse ponto, descreveremos brevemente as discussões das epistemologias feministas que permitiram a formulação de métodos por teóricas como Bartlett, além das configurações presentes no Direito que nos alertam para a importância de inserir perspectivas feministas de análise nessa área.

Patricia Hill Collins, socióloga estadunidense, ao tratar dos processos de validação de conhecimento nos espaços acadêmicos, nomeia-os como formas de “abordagem positivista” (COLLINS, 2000, p. 255). Nesse viés, o saber científico exigiria que o cientista se desapegasse de seus valores, interesses e emoções geradas por sua classe, raça e gênero, utilizando-se apenas de sua racionalidade. Além disso, os resultados válidos seriam aqueles que chegassem a generalizações objetivas, que fossem capazes de sobreviver aos ataques e às críticas nas discussões acadêmicas, produzindo verdades absolutas (COLLINS, 2000, p. 255) .

Essa é uma reflexão importante para entender as formas como os corpos se posicionam (ou são posicionados) nesse processo de formação de conhecimento científico. $O$ fazer científico denunciado por Collins atende a uma lógica que cinde corpo e mente, neutralizando o fato de que o cientista é ser corporificado, com experiências, ocupante de um estrato social, que se identifica a partir de concepções de gênero, raça e classe. Da mesma forma, o objeto desse conhecimento é personificado, pois acompanha os marcadores do sujeito que o produz. Assim, os corpos, sujeito e objeto do saber, estão relacionados no processo de construção de conhecimento.

No Direito, essa forma universalizante de produção de conhecimento é bastante generalizada. Carol Smart, socióloga britânica que pensou as relações entre feminismo e

\footnotetext{
${ }^{6}$ A crítica apresentada por Collins é uma das bases para as produções da epistemologia feminista, presente nas discussões de diversas pesquisadoras desde os anos 1980. Para aprofundar o tema, ver Bandeira (2008).
} 
Direito e as tensões dessa interação ${ }^{7}$, busca relacionar os modos de exercício de poder das ciências e do Direito. Para ela, esses dois campos se entrecruzam em suas pretensões de dizer o que é "verdade" (claim to truth), e isso se materializa, para ambos, em forma de poder. No caso do Direito, sua credibilidade para estabelecer verdades está relacionada ao uso de método, linguagem e sistema de resultados próprio (SMART, 1989, p. 9). Sua capacidade de dizer o que é real, o que deve fazer parte do discurso e da prática jurídica é uma forma importante de manifestação de poder não apenas nos textos de lei e decisões, mas principalmente porque, dizendo o que é a verdade, outros saberes e experiências são desqualificados, considerados desinteressantes para os discursos jurídicos (SMART, 1989, p. 11).

Apesar de as discussões de Smart estarem relacionadas à realidade europeia dos anos $1980 \mathrm{e}$, portanto, atreladas às lutas iniciais e contextuais do pensamento feminista em tensão com o Direito, Fabiana Severi, que pesquisa tais relações no Brasil, considera as formulações da britânica ainda atuais e relevantes para o debate nacional, especialmente quanto à possibilidade de movimentos como os feministas desafiarem o poder do Direito (SEVERI, 2017, p. 75). Para Severi (2017, p. 72), há uma presunção que, ainda hoje, é amplamente aceita "de que o método de interpretação e aplicação da lei é neutro, objetivo e imparcial e, por isso, sempre capaz de produzir uma decisão correta". Nessa lógica, o Direito se manifesta por meio do uso de métodos lógico-formais que buscam a formação de um saber dogmático, preocupado com a análise das condições de validade e aplicação das normas (DIAS; GUSTIN, 2006, p. 11), sem levar em consideração os aspectos históricos, políticos, sociais e culturais que permeiam a produção jurídica (MACHADO, 2009, p. 79).

Os aspectos acima apontados foram e ainda são alvo de críticas por parte de teóricas feministas brasileiras e estrangeiras que, sob diversas vertentes ${ }^{8}$, questionam a ideia de neutralidade, o princípio da igualdade (usado como parâmetro nas formulações judiciais e acadêmicas sobre questões fundamentais do Direito), os binarismos legais, como "público-privado" e "sujeito e objeto", além da tendência à desnaturalização de categorias legais pela formulação de parâmetros homogeneizantes como dos "sujeitos de direitos" (SEVERI, 2017, p. 52).

Camilla de Magalhães Gomes, pesquisadora brasileira sobre o tema, detém-se em algumas construções presentes na dogmática que são constantemente reproduzidas por

\footnotetext{
${ }^{7}$ Além do trabalho citado neste artigo, outra produção relevante da autora sobre o tema é o artigo A mulher do discurso jurídico, cuja tradução foi publicada em 2020.

${ }^{8}$ Os trabalhos de Ramos (2020) e de Campos e Severi (2019) são exemplos de contribuições recentes para a sistematização das críticas feministas ao Direito, desde perspectivas e ramos diversos deste campo. Já sobre os dialógos entre feminismos e Ciências Criminais, citamos o trabalho de Martins e Gauer (2020).
} 
A "pergunta pela mulher" nas ciências criminais: Contribuições da metodologia feminista para o campo do direito

seus estudiosos como máximas fundamentais, como é o caso do "sujeito de direitos" e da "pessoa humana". Entretanto, essas visões universalizantes se adequam a poucos, ou mesmo a nenhum, dos sujeitos reais que vão ser alvo do sistema de justiça, que sofrerão as consequências da norma universal. A representação em torno da racionalidade e livre escolha do "cidadão universal capaz de transcender o corpo e o sentimento" (YOUNG, 2011, p. 109) nega aspectos do humano, o que aparentemente os exclui da esfera do Direito, mas, ao mesmo tempo, constitui as hierarquias de seu funcionamento.

Segundo Gomes, essas categorizações tão naturais na escrita do Direito se formam a partir de matrizes que negam ou esquecem, em suas significações, a existência de um corpo, ao propor um humano puramente racional. Esse é um ponto crucial para se entender as subjetividades que o Direito produz, apesar da negação constante de sua existência e influência nesse saber. A supressão do corpo para a formação de sujeitos de direitos e deveres como objeto de estudo do campo jurídico faz que não sejam considerados níveis diferentes de inclusão e exclusão social e as vulnerabilidades presentes em diferentes grupos, retirando a própria humanidade desses corpos, que não se encaixam no modelo ideal (GOMES, 2019, p. 898). Esse processo de desumanização leva à reprodução de concepções como a do homem negro violento e criminoso e da mulher vítima, por exemplo (GOMES, 2019, p. 892). Gênero, raça, classe, nacionalidade e outros marcadores são essenciais para entender quais corpos não se encaixam nos moldes de sujeitos de direitos da forma como idealizados, mas se amoldam perfeitamente a outros, especialmente aos ligados ao sistema criminal.

Assim, é importante historicizar esses corpos, entender quem detém o poder de produzir conhecimento válido no Direito, a partir de quais posições essa voz fala e quais são excluídas e como esses objetos de estudo se conformam ou não às proposições normativas estudadas, produzidas por esse Direito. $\mathrm{O}$ delineamento de conhecimentos mais inclusivos no Direito envolve um processo de mão dupla, de desconstrução e reconstrução (SARDENBERG, 2001, p. 10) em que o diálogo entre epistemologias e métodos é fundamental. Pensar em métodos legais feministas é impossível sem que antes sejam questionadas as próprias noções tradicionais pelas quais o Direito se estrutura enquanto ciência.

As epistemologias feministas, enquanto teorias que se formam a partir da práxis política (SARDENBERG, 2001, p. 3), acabam por se contrapor a fundamentos básicos das ciências tradicionais, fundadas na neutralidade, na universalidade e no distanciamento do pesquisador de seu objeto de estudo. Isso permite que elas possam ver a partir de outros lugares, normalmente excluídos do interesse científico, pensar e questionar outras realidades e construir novos parâmetros ao que se entende como ciência. $\mathrm{O}$ destaque de algumas epistemologias feministas para a experiência vivida por seus grupos sociais e o enfoque nos discursos de pessoas que não estão inseridas na 
academia como fonte de conhecimento são exemplos dessa contraposição. Esse movimento é importante, uma vez que possibilita rupturas e mudanças no campo, na sua forma de produção e aplicação, que podem conduzir a uma maior aproximação com a realidade social e as demandas de grupos marginalizados.

\section{O MÉTODO LEGAL FEMINISTA PROPOSTO POR KATHARINE BARTLETT}

Dentro da proposta de métodos e epistemologias feministas, aprofundamo-nos naquela apresentada pela autora estadunidense Katharine Bartlett, em seu artigo Feminist Legal Methods (BARLETT, 1990). Partindo do questionamento acerca da neutralidade da produção jurídica, ela sugere trazer a mulher para o centro da discussão, apresentando um método que pudesse questionar a forma tradicional de produção de normas, textos e decisões desde problemáticas feministas. Sobre os motivos pelos quais considera relevante o estudo do método por feministas dentro do Direito, a autora diz:

\footnotetext{
Feministas não podem ignorar o método, porque se elas buscam desafiar estruturas de poder com os mesmos métodos que têm definido o que conta dentro dessas estruturas, elas podem, ao contrário recriar as estruturas de poder ilegítimas. Método também importa porque sem a compreensão sobre métodos feministas, suas reivindicações no Direito não serão percebidas como legítimas ou 'corretas'. [...] Pensar sobre método é empoderador. Quando eu me forço a explicar o que eu faço, estou mais propícia a descobrir como melhorar aquilo que antes posso ter deixado de lado (BARTLETT, 1990, p. 831, tradução nossa).
}

Para a autora, os métodos tradicionais de produção jurídica têm dado grande importância para a previsibilidade, certeza e rigidez das normas. Ao contrário, os métodos feministas partem da crítica de que as normas postas representam as estruturas de poder e, portanto, cogitam a possibilidade de flexibilização delas, tendo em vista a existência e identificação de pontos de vista ausentes (BARTLETT, 1990, p. 832), já que são excluídos ou marginalizados nessa estrutura. Desde essa premissa, Bartlett propõe como método a utilização de três eixos para análise do Direito, quais sejam, a pergunta sobre a mulher, o raciocínio prático e o aumento de consciência.

Por meio da pergunta pela mulher, busca-se analisar como o Direito, muitas vezes, é não apenas não neutro, mas sim masculino, expondo reflexos ocultos da produção jurídica que, se não discrimina abertamente, perpetua comportamentos sociais que relegam à mulher um lugar de subordinação. Para tanto, ela apresenta algumas perguntas que podem ser "feitas ao texto" em análise, dentre as quais: "As mulheres foram negligenciadas nesse texto?; Se foram, de que maneira isso aconteceu?; Como essa omissão pode ser corrigida?; Que diferença haveria se fosse corrigida a omissão?" 
A "pergunta pela mulher" nas ciências criminais: Contribuições da metodologia feminista para o campo do direito

(BARTLETT, 1990, p. 837). A ideia, portanto, é entender se e como esses textos (normativos, decisórios, acadêmicos) deixaram de levar em conta ${ }^{9}$ outras realidades que não a daqueles que os produzem.

Já o raciocínio prático busca expor as múltiplas perspectivas de um problema, evitando generalizações típicas da análise jurídica. Nas palavras da autora, esse eixo "vê os detalhes particulares não como inconsistências ou incômodos irrelevantes que impedem a aplicação lógica de regras fixas [...]. Fatos novos, ao contrário, apresentam oportunidades para interpretações aprimoradas e integrações” (BARTLETT, 1990, p. 851). Para que isso seja feito, é necessário analisar os textos fora de suas caixas de generalização, tão comuns ao Direito, que tenta criar padrões para a aplicação das normas. Perguntas, como: "Quando perspectivas de gênero foram inseridas no texto, de que maneira isso ocorreu?; Essa inserção levou em consideração ideias generalizantes acerca do gênero?", podem auxiliar na obtenção de respostas.

Por último, a tomada de consciência significa a construção de conhecimento a partir da articulação das diversas experiências das mulheres, bem como de lugarescomuns nessas histórias, sendo um meta-método, uma base para a aplicação dos demais eixos. Ele é útil para reconstruir os textos analisados, demonstrando a possibilidade de criação de uma escrita firmada em novos e diferentes objetos, mais aberta às especificidades de cada caso, que oriente a leitora na formação de um conhecimento mais crítico do Direito.

Como apontado por Bartlett, o uso desse método não tem como objetivo desconsiderar a importância de outras formas de construção científica, ou mesmo excluir as experiências masculinas. $\mathrm{O}$ que se pretende é abrir possibilidades de análise diversificadas, ao invés de limitá-las a categorias previamente prescritas (BARTLETT, 1990 , p. 857-858). Ao mesmo tempo, essa proposta se mostra como uma alternativa metodológica feminista, na medida em que questiona as formas tradicionais de conhecimento e busca fazer perguntas a partir dos interesses de grupos não dominantes, por meio de caminhos metodológicos baseados em teorias feministas ${ }^{10}$.

\footnotetext{
${ }^{9}$ No texto, a autora entende essa questão como uma "falha" do Direito. Entretanto, levando em consideração as discussões anteriores sobre as disputas e conformações de poder de dizer o que é verdade no Direito (SMART, 1989; SEVERI, 2017), podemos problematizar o uso do termo falha.

${ }^{10}$ Bartlett (1990, p. 832) analisa quatro teorias do conhecimento presentes na escrita legal feminista: o empirismo racional (rational empirism), a epistemologia do ponto de vista (standpoint epistemology), o pósmodernismo (postmodernism) e a posicionalidade (positionality). Ao final, conclui que a teoria da posicionalidade é mais relevante para construção do conhecimento feminista no Direito, sendo esta a base para se pensar os métodos apresentados por ela.
} 


\section{A UNIVERSALIZAÇÃO DA "MULHER": CATEGORIAS DE GÊNERO E POSICIONALIDADES NA METODOLOGIA FEMINISTA}

Um dos questionamentos que podem ser levantados quanto ao emprego de métodos feministas nas Ciências Criminais é sobre a necessidade de se fazer um recorte de gênero nos materiais de pesquisa, sendo essas técnicas metodológicas aplicáveis apenas quando se fala da criminalização de mulheres. Essa é uma pergunta relevante, uma vez que muitos dos textos que se propõem a abordar o crime não têm como objetivo discutir especificamente a criminalidade feminina, tampouco apontar as marcas de gênero das (e nas) análises.

A discussão atravessa escolhas metodológicas, entretanto uma metodologia feminista nas Ciências Criminais não é útil apenas quando o objetivo é tratar de mulheres, mas também para pensar masculinidades e como os marcadores de gênero (em intersecção com outros) são mobilizados. Assim, é válido perguntar pela mulher, e esse pode ser um dos objetivos quando da aplicação dos eixos trazidos por Bartlett. No entanto, podemos deslocar as categorias que conformam suas perguntas para levar em consideração outras hierarquias de gênero que operam no discurso penal.

A articulação das categorias mulher criminosa e gênero é central na construção da pesquisa aqui proposta. Bartlett propõe que perguntemos pela mulher, no entanto essa não é uma categoria estática do método, uma vez que a própria autora reconhece que ela deve ser considerada juntamente a diversos outros marcadores, o que nos levaria à "pergunta pelos excluídos" (BARTLETT, 1990, p. 847). Mesmo no caso de pesquisas dentro das Ciências Criminais, que busquem abordar a criminalidade feminina, utilizar a categoria mulher, sem considerar gênero como um aspecto relevante, tornaria a análise deficiente.

Historicamente, o conceito gênero não teve como objetivo substituir a categoria sexo, mas suplementá-la (COSTA, 2003, p. 170). Buscou explicar aquilo que era socialmente construído na distinção entre masculino e feminino, enquanto o sexo estaria relacionado a características biológicas, sendo incorporado pelo gênero (NICHOLSON, 2000, p. 11). Há uma tentativa de negar as produções deterministas acerca do masculino e do feminino, mas, como explica Nicholson, o sexo, nessas novas teorias de construção social, ainda possuía papel de grande importância: "o de provedor do lugar onde o gênero seria supostamente construído”. Judith Butler, filósofa estadunidense, critica o binarismo de sexo e gênero, questionando a origem natural do primeiro e o caráter estático do segundo, entendendo o gênero como "um ponto relativo de convergência entre conjuntos específicos de relações, cultural e historicamente convergentes" (BUTLER, 2003, p. 29).

Nicholson (2000, p. 24) fala de um fundacionalismo biológico ao tratar das 
A "pergunta pela mulher" nas ciências criminais: Contribuições da metodologia feminista para o campo do direito

primeiras teorias negadoras do determinismo, uma vez que, apesar do reconhecimento de diferenças entre as mulheres, elas também apontam a "existência de certos aspectos comuns entre as mulheres". Ela explica que havia uma tendência de se pensar o gênero como fator de união entre todas as mulheres (as características comuns), e os aspectos de raça e classe como indicativos do que elas teriam de diferente. Entretanto, essa diferenciação não é suficiente. É necessário pensar que as diferenças não estão apenas entre as mulheres, mas dentro delas próprias, colocando gênero e mulher como variáveis, e não qualidades estáticas a partir das quais outras se manifestam.

De forma semelhante ${ }^{11}$, Butler (2003, p. 20) fala das intersecções do gênero com "modalidades raciais, classistas, étnicas, sexuais e regionais de identidades discursivamente constituídas" e questiona a necessidade de uma base universal identificável em qualquer lugar, independentemente da cultura, ou mesmo de uma opressão comum. Contra isso, propõe que as políticas feministas entendam a identidade como uma construção variável e um pressuposto metodológico (BUTLER, 2003, p. 23) a ser pensado junto a esses outros marcadores culturais e históricos.

As críticas apresentadas pelas duas autoras também estão presentes e foram em grande parte desenvolvidas na tradição teórica feminista negra (COLLINS, 2000), especialmente na elaboração da noção de interseccionalidade. $O$ afastamento da categoria mulher e a substituição pela categoria gênero desafia também os estatutos tradicionais em torno da constituição do saber. Feministas decoloniais, como Yuderkys Miñoso (2020), questionam propostas feministas que, mesmo inconscientemente, colocam a mulher como sujeito universal, uniformizando a condição de todas elas e implantando a imagem da mulher em constante estado de sujeição com relação ao homem, a despeito de qualquer diferença, espaço e tempo (MIÑOSO, 2020, p. 110113).

A partir dessas reflexões e na esteira do que propõe Alcoff (1988, p. 433), mobilizamos a categoria mulher como uma posicionalidade. Uma categoria relacional, em que as diferentes posições sociais intersectadas ajudam na construção do que é "ser mulher" a partir de uma determinada experiência. Buscamos estabelecer "formas de identificação em torno da categoria mulher" (COSTA, 2002, p. 76).

Da mesma forma, pensamos gênero em nosso trabalho de forma posicionada. $\mathrm{O}$ gênero é ferramenta potente para compreensão da configuração da mulher na criminalidade sob o ponto de vista dos textos das Ciências Criminais. Nesse contexto, pensar e dialogar com o gênero é importante, uma vez que a escrita sobre o crime e as

\footnotetext{
${ }^{11}$ Apesar de divergirem em diversos pontos, as teorias de Butler (2003) e Nicholson (2000) dialogam na tentativa de desconstruir os essencialismos em torno do gênero e de seu tratamento como categoria única da qual se parte nos estudos feministas.
} 
prisões está marcada por ele. Essas produções não são neutras, mas permeadas pelas ideias de violência e organização geralmente atribuídas a sujeitos masculinos:

\begin{abstract}
A escrita sobre crime, bandidagem e cadeia é masculina, está imersa no patriarcado e reproduz a linguagem hegemônica do gênero. A pesquisa e a escrita sobre cadeia são de homens e sobre homens. [...] O campo do direito penal, da sociologia da punição e, mesmo, da criminologia é dominado por autores homens. As cadeias estão abarrotadas de homens presos. Crime, castigo e autoria são questões masculinas. Mas é a segunda versão da tese a que mais me interessa - a hegemonia dos homens impôs uma forma de falar sobre cadeia: a linguagem é a do sangue, da denúncia e do escândalo. [...] Peço o encantamento de quem faz desaparecer o medo para dar lugar ao reconhecimento: escritura e vidência importam para tornar visível o escondido ou desaparecido (DINIZ, 2015, p. 584).
\end{abstract}

Nesse processo de encantamento proposto pela autora, perguntar pela criminosa e escrever sobre ela também significa considerar a realidade do que é a escrita penal e dos motivos pelos quais ela se desenvolve dessa forma. Dialogar com o gênero na escrita feminista permite, então, que evidenciemos nosso "objeto" de estudo, sem cair nos mesmos problemas das escritas tradicionais, ou seja, as visões unidimensionais, essencialistas e excludentes. Pensamos o gênero, nesse contexto, como uma categoria analítica constitutiva das relações sociais, que as significa enquanto relações de poder (SCOTT, 1995, p. 86). Seguindo as reflexões de Scott (1995), Fabiana Severi entende o gênero em sua pesquisa como uma

[...] possibilidade de aprofundar os sentidos construídos sobre o masculino e o feminino, transformando "homens" e "mulheres" em problemáticas, e não em categorias fixas, dadas de antemão, a partir daí, é possível investigarmos, por exemplo: como o gênero organiza as relações sociais, significa as coisas e define as identidades pessoais e como os sentidos e significados construídos com base nas diferenças sexuais são hierarquizados [...] (SEVERI, 2016, p. 83).

Assim, propomos redimensionar a categoria mulher do método de Bartlett em dois sentidos: 1) colocando a mulher como categoria das perguntas em diálogo com gênero, o que nos permite discutir masculinidade, orientação sexual, cisgeneridade etc.; 2) concebendo a categoria mulher desde uma perspectiva interseccional, levando em consideração o gênero em produção com raça, classe, nacionalidade, dentre outros marcadores.

Para além dessas discussões, que envolvem as escolhas metodológicas na construção de uma ciência feminista e posicionada, há também desafios particulares no trabalho com a criminalidade feminina. Quando refletimos sobre a criminalidade, a partir das nossas experiências, falamos, de forma geral, de uma posição de privilégio em relação às pessoas que estudamos, privilégios garantidos pela branquitude, que permite a inserção no mundo acadêmico e dá condições para produzir conhecimento sobre o 
A "pergunta pela mulher" nas ciências criminais: Contribuições da metodologia feminista para o campo do direito

outro. Esse mesmo lugar de privilégio faz que investiguemos e localizemos a criminalidade nos excluídos. Assim, buscamos reposicionar nossas lentes para os sujeitos e temas que estudamos, de modo a não legitimar essa forma de conhecimento que os coloca como a outra.

Talvez esse seja o maior dos problemas quando buscamos estudar a criminalidade a partir de visões posicionadas, já que, como explica Haraway,

[...] há um sério perigo em se romantizar e/ou apropriar a visão dos menos poderosos ao mesmo tempo que se alega ver desde sua posição. Ter uma visão de baixo não é algo não problemático [...] mesmo que 'nós' 'naturalmente' habitemos o grande terreno subterrâneo dos saberes subjugados (HARAWAY, 1995, p. 22-23).

Nesse sentido, os pensamentos decoloniais nos alertam para a possibilidade de também produzirmos racionalidades excludentes e opressoras e da importância de utilizarmos categorias e teorias que emergem de experiências subalternizadas e que possam explicar a realidade de forma generalizada, mas sem universalizá-la (CURIEL, 2020, p. 134).

\section{ARRANJOS E DESARRANJOS NA CONSTRUÇÃO DE UMA METODOLOGIA FEMINISTA NO SUL GLOBAL}

Existem algumas dificuldades em traduzir o método de Bartlett à nossa realidade. Isso porque ele está situado no contexto norte-americano dos anos 1990 e foi construído para analisar o Direito produzido sob a common law, que guarda muitas diferenças do formato de civil law brasileiro. Quando o Direito se constrói com ênfase em precedentes judiciais, como é o caso dos Estados Unidos, as concepções ideológicas dos julgadores podem ser vistas com mais facilidade, o que permite o estudo posterior de sua influência no processo decisório. Também é possível encontrar mais facilmente as representações de gênero, uma vez que os casos que dão forma ao Direito possuem atores definidos e caracterizados, diferentemente do Brasil, que se pauta na "letra da lei".

No Direito Penal brasileiro, tem-se fortalecido, gradualmente, a utilização de precedentes - prática que ecoa nas pesquisas por meio da citação de julgados emblemáticos e no uso de decisões judiciais como material de análise. No entanto, esse aspecto de universalização da lei penal, traduzida em sujeitos ativos genéricos dos tipos penais, ainda é bastante forte e dificulta a aplicação do método. Esse processo de transposição também envolve considerar os choques de história e cultura, que se refletem nas ideias de desenvolvimento teórico da autora e que precisam ser lidas à luz da realidade brasileira. 
Impossível, então, pensar uma Ciência Criminal posicionada sem relacionar as teorias feministas "de fora" ao nosso saber decolonial, proveniente de feministas brasileiras e latino-americanas. Elas partem da crítica de que as vozes evocadas na ciência tradicional, que se coloca como neutra e universal, emanam de um olhar masculino, branco e heterossexual, que está longe de alcançar as titulações que atribuem a si mesmas. Reconhecem a importância de introduzir e dialogar com autoras estrangeiras, mas denunciam que há um domínio do conhecimento que se divide geopoliticamente, sendo a Europa e os Estados Unidos o centro de sua produção, caracterizando o que se denomina "colonialidade do saber" (CURIEL, 2020, p. 128).

Essa lógica silencia e invisibiliza conhecimentos de populações subalternizadas, tornando suas experiências meros objetos de pesquisa, matéria-prima para análises supostamente críticas, movidas pelos verdadeiros detentores do saber (CURIEL, 2020, p. 133). A interpretação de colonialidade do saber dada pela antropóloga dominicana Ochy Curiel é, portanto, de que uma posição decolonial feminista que rompe com o poder colonial considera o gênero, a raça, a classe não apenas como eixos de diferença nos quais se posicionam nossos sujeitos-objetos, mas como constituintes de uma "episteme moderna colonial" (CURIEL, 2020, p. 133). O rompimento com essa episteme pressupõe entender, como propõe Lugones (2008), que as pesquisas feministas em nosso campo não são sobre categorias analíticas, mas sobre realidades vividas.

Esse deslocamento é importante quando pensamos a criminalidade, uma vez que falamos de sujeitos que estão à margem da sociedade, tanto pela exclusão que o rótulo de criminosa cria quanto pelo fato de que a maioria dessas pessoas já se encontra marginalizada desde antes da criminalização. Há uma constante modulação dos corpos desses outros pelo sistema de justiça criminal que também está relacionada à nossa constituição enquanto nação colonizada, que carrega as marcas da escravidão. Os estudos decoloniais nos ajudam a entender essa dinâmica ao mostrar que, pelos processos de colonização e dominação, esses corpos têm sua humanidade questionada, têm retirados de si qualquer valor ou originalidade (FANON, 2008, p. 94). No contexto latino-americano, Gonzalez (1988, p. 74) argumenta que a consciência do racismo que impera nessas formulações é o passo decisivo para que possamos produzir outras formas de conhecimento.

Assim, um aspecto importante da ciência feminista está em colocar em foco as experiências desses sujeitos. Por isso, os métodos empíricos são tão importantes para a formação das teorias feministas e essenciais para a aplicação da proposta de Bartlett. Perguntar pela criminosa significa também buscar suas vozes, diretamente (em diálogo com elas) ou indiretamente, por meio de outras produções empíricas que o fizeram.

Pensar em metodologias feministas nas Ciências Criminais é construção. Partimos de teorias e aspectos metodológicos desenvolvidos por outras autoras, mas, 
A "pergunta pela mulher" nas ciências criminais: Contribuições da metodologia feminista para o campo do direito

nesse caminhar, fazemos escolhas e desenhos metodológicos específicos, posicionando a análise desde a formulação da pergunta. Assim, como aponta Alice Walker, citada por Collins (2000, p. 19, tradução das autoras), "ao mesmo tempo em que apontamos a direção do que queremos ver, devemos seguir essa mesma direção”. Esse é um duplo trabalho que pode ser especialmente desafiador, mas que também tem potencial para contribuir para a formação de alternativas de dizer e pesquisar o Direito.

\section{CONSIDERAÇÕES FINAIS}

Neste trabalho, seguimos as reflexões das autoras com as quais dialogamos e aquelas que apareceram conforme mobilizamos uma possibilidade de método feminista para o estudo das Ciências Criminais, na tentativa de produção de saberes localizados. Localização nos "espaços do conhecimento" em que cada uma de nós nos colocamos e somos colocadas, em diferentes épocas, contextos, países e marcadores que nos formam. Para pensar sobre a constituição de uma categoria em determinado campo do saber, mobilizamos questões epistemológicas e políticas que delineiam o próprio campo, estranhando a universalidade e neutralidade das categorias jurídicas, a partir da hierarquia na produção e legitimação do conhecimento.

No Direito, em que essas concepções são generalizadas nos saberes dogmáticos, a construção de uma linguagem que articula sexo, gênero, raça e classe passa pela mudança de postura, em primeiro lugar, daquele que produz conhecimento. Nesse contexto, pensar a partir de um corpo que ocupa lugares sociais significa produzir a partir de posicionalidades. Posição envolve não esconder vulnerabilidades, não se utilizar de uma política de fechamento, evitar lugares simplistas. Dar melhores explicações, a partir de uma perspectiva crítica que explicita de quais experiências e visões a pesquisadora parte. Posição não pressupõe abandonar a objetividade ou a racionalidade na produção científica, mas utilizá-las de forma localizada, isto é, visões desde algum lugar (HARAWAY, 1995, p. 33-34).

Para isso, não é necessário que as pesquisadoras abandonem estratégias de pesquisa já existentes, mas que deem a elas novas roupagens e permitam que novas personagens possam ocupar a cena. Propostas feministas como a de Bartlett dialogam com um olhar crítico que reconhece o espaço social como não homogêneo e marcado por hierarquias de raça, gênero, classe, nacionalidade e etnia. Para atingi-lo, a utilização de novos métodos de pesquisa parece ser de grande relevância, uma vez que eles permitem o questionamento e a reconstrução das bases pelas quais o Direito e as Ciências Criminais se colocam enquanto saberes válidos e científicos.

A construção de uma ciência feminista ou de epistemologias feministas no Direito está ancorada no trabalho de uma gama de pesquisadoras que vêm questionando os 
métodos científicos tradicionais e denunciando o modo como marcadores de gênero, raça e classe operam na formação desse saber. Em nossa proposta, pensar um quarto para as Ciências Criminais desde uma perspectiva feminista significa levar em consideração as marcas que formam o nosso saber e também a realidade de criminalização que exploramos. Esse quarto deve ser guarnecido com as experiências desde as quais produzimos, experiências à margem de saberes privilegiados. Para além de tudo isso, um quarto todo nosso não pode ser pensado desde a perspectiva da branquitude, sem que eles sejam habitados pelos corpos submetidos ao empobrecimento e à negação de sua capacidade de desenvolver saberes (MIÑOSO, 2020, p. 109), corpos que ocupam os quartos de despejo descritos por Carolina Maria de Jesus ou o lixo da qual Lelia Gonzalez enuncia.

\section{REFERENNCIAS}

ALCOFF, Linda. Cultural Feminism versus Poststructuralism: the identity crisis in feminist theory. Signs, v. 13, n. 3, 1988.

BANDEIRA, Lourdes. A contribuição da crítica feminista à ciência. Revista de Estudos Feministas, v. 16, n. 1, p. 207-230, jan./abr. 2008.

BARTLETT, Katharine T. Feminist Legal Methods. Harvard Law Review, v. 103, n. 4, p. 829-888, fev. 1990. Disponível em: https://www.jstor.org/stable/1341478?seq=1. Acesso em: 10 set. 2019.

BUTLER, Judith. Problemas de gênero: feminismo e subversão da identidade. Rio de Janeiro: Civilização Brasileira, 2003.

CAMPOS, Carmen Hein de; SEVERI, Fabiana Cristina. Violência contra as mulheres e a crítica jurídica feminista: breve análise da produção acadêmica brasileira. Revista Direito e Práxis, v. 10, n. 2, p. 962-990, 2019.

CHANTER, Tina. Gênero: conceitos-chave em filosofia. Porto Alegre: Artmed, 2011.

COLLINS, Patricia Hill. Black Feminist Thought. 2. ed. New York: Routledge, 2000.

COSTA, Cláudia de Lima. Paradoxos do gênero. Revista Gênero, v. 4, n. 1, p. 169-177, 2. sem., 2003.

COSTA, Cláudia de Lima. O sujeito no feminismo: revisitando os debates. Cadernos Pagu, n. 19, p. 59-90, 2002. Disponível em https://www.scielo.br/scielo.php?pid=S0104-83332002000200004\&script=sci_arttext. Acesso em: 10 jun. 2020. 
A "pergunta pela mulher" nas ciências criminais: Contribuições da metodologia feminista para o campo do direito

CURIEL, Ochy. Construindo metodologias feministas a partir do feminismo decolonial. In: HOLLANDA, Heloisa Buraque de (org.). Pensamento feminista hoje: perspectivas decoloniais. Rio de Janeiro: Bazar do Tempo, 2020. p. 121-138.

DAVIS, Angela. Mulheres, raça e classe. São Paulo: Boitempo, 2016.

DIAS, Maria Tereza Fonseca; GUSTIN, Miracy Barbosa de Sousa. (Re)pensando a pesquisa jurídica: teoria e prática. 2. ed. Belo Horizonte: Editora Del Rey, 2006.

DINIZ, Débora. Pesquisas em cadeia. Revista Direito GV, v. 11 n. 2, p. 573-586, jul./dez. 2015. Disponível em https://www.scielo.br/scielo.php?pid=S180824322015000200573\&script=sci_arttext\&tlng=pt. Acesso em: 3 mar. 2020.

FANON, Frantz. Pele negra, máscaras brancas. Salvador: EDUFBA, 2008.

GOMES, Camilla de Magalhães. Os sujeitos do performático jurídico: relendo a dignidade da pessoa humana nos marcos de gênero e raça. Revista Direito e Práxis, v. 10, n. 2, p. 871-905. 2019. Disponível em https://www.scielo.br/scielo.php?pid=S2179$89662019000200871 \&$ script=sci_arttext\&tlng=pt. Acesso em: 20 maio 2020.

GONZALEZ, Lélia. Racismo e sexismo na cultura brasileira. Revista Ciências Sociais Hoje, Anpocs, p. 223-244, 1984.

GONZALEZ, Lélia. A categoria político-cultural da Amefricanidade. Tempo Brasileiro, n. 92-93, p. 69-82, jan. /jun. 1988.

HARAWAY, Donna. Saberes localizados: a questão da ciência para o feminismo e o privilégio da perspectiva parcial. Cadernos Pagu, n. 5, p. 7-41, 1995. Disponível em https://periodicos.sbu.unicamp.br/ojs/index.php/cadpagu/article/view/1773. Acesso em: 16 abr. 2020.

HARDING, Sandra. ¿Existe un método feminista?. In: HARDING, Sandra (ed.). Feminism and Methodology. Indianapolis: Indiana University Press, 1987. p. 9-34.

HARDING, Sandra. ¿Existe un método feminista?. Epílogo. In: HARDING, Sandra (ed.). Feminism and Methodology. Indianapolis: Indiana University Press, 1998. p. 32 34.

JESUS, Carolina Maria de. Quarto de despejo: diário de uma favelada. São Paulo: Editora Ática, 1992.

JESUS, Carolina Maria de. Casa de alvenaria: diário de uma ex-favelada. Rio de Janeiro: Editora Paulo de Azevedo, 1961. 
LUGONES, María. Colonialidad y Género: Hacia un feminismo descolonial. In: MIGNOLO W. (comp.). Género y Descolonialidad. Buenos Aires: Del signo, 2008.

MIÑOSO, Yuderkys Espinosa. Fazendo uma genealogia da experiência: o método rumo a uma crítica da colonialidade da razão feminista a partir da experiência na América Latina. In: HOLLANDA, Heloisa Buarque de (org.). Pensamento feminista hoje: perspectiva decoloniais. Rio de Janeiro: Bazar do Tempo, 2020. p. 97-118.

MACHADO, Antônio Alberto. Ensino jurídico e mudança social. 2. ed. São Paulo: Atlas, 2009.

MARTINS, Fernanda; GAUER, Ruth. Poder punitivo e feminismo: percursos da criminologia feminista no Brasil. Revista Direito e Práxis, Rio de Janeiro, v. 11, n. 2, p. $145-178,2020$.

MENDES, Soraia da Rosa. Processo Penal Feminista. São Paulo: Atlas, 2020.

MOSER, Benjamin. Clarice, uma biografia. São Paulo: Cosac Naify, 2009.

MOSER, Benjamin. Clarice, uma biografia. São Paulo: Companhia das Letras, 2017.

NICHOLSON, Linda. Interpretando gênero. Revista Estudos Feministas, v. 8, n. 2, p. 9-41, 2000. Disponível em https://www.jstor.org/stable/43596547?seq=1. Acesso em: 16 abr. 2020.

RAMOS, Marcelo Maciel. Teorias Feministas e Teorias Queer do Direito: gênero e sexualidade como categorias úteis para a crítica jurídica. Revista Direito e Práxis, Ahead of print, Rio de Janeiro, 2020.

SARDENBERG, Cecília Maria Bacellar. Da crítica feminista à crítica a uma ciência feminista?. In: ENCONTRO DA REDOR, 10., 2001, Salvador. Anais [...]. Salvador: Universidade Federal da Bahia. Repositório Institucional UFBA, 2001. Disponível em: https://repositorio.ufba.br/ri/handle/ri/6875. Acesso em: 21 jun. 2020.

SCOTT, Joan. Gênero: uma categoria útil de análise histórica. Educação e Realidade, v. 20, n. 2, jul./dez. 1995.

SEVERI, Fabiana Cristina. O gênero da justiça e a problemática da efetivação dos direitos humanos das mulheres. Revista Direito e Práxis, v. 7, n. 13, p. 80-115, 2016.

SEVERI, Fabiana Cristina. Enfrentamento à violência contra as mulheres e à domesticação da Lei Maria da Penha: elementos do projeto jurídico feminista no Brasil. 2017. Tese (Livre-Docência). Faculdade de Direito de Ribeirão Preto, Universidade de São Paulo, Ribeirão Preto, 2017. 
A "pergunta pela mulher" nas ciências criminais: Contribuições da metodologia feminista para o campo do direito

SMART, Carol. A mulher do discurso jurídico. Revista Direito e Práxis, v. 11, n. 02, p. 1418-1439, 2020.

SMART, Carol. Feminism and the power of law. Londres: Routledge, 1989.

SILVA, Rafael Guimarães Tavares da. Des(p)ejo das palavras: relendo os primeiros diários de Carolina Maria de Jesus. Revista Estudos Feministas, v. 27, n. 2, set. 2019. Disponível em: https://periodicos.ufsc.br/index.php/ref/article/view/1806-95842019v27n254825. Acesso em: 1 out. 2020.

WOOLF, Virginia. Um teto todo seu. São Paulo: Tordesilhas, 2014.

YOUNG, Iris Marion. Justice and the politics of difference. Princeton: Princeton University Press, 2011.

\section{NOTA}

Trata-se de co-autoria entre orientanda e orientadora de artigo fruto de pesquisa de mestrado. A produção de dados foi realizada por Leticia Ferreira (mestranda), enquanto Ana Gabriela Braga foi responsável pelo planejamento e recorte do texto. A elaboração teórica e metodológica, assim como a escrita do texto foi compartilhada por ambas pesquisadoras.

Como citar este documento:

FERREIRA, Letícia Cardoso; BRAGA, Ana Gabriela Mendes. A "pergunta pela mulher" nas ciências criminais: Contribuições da metodologia feminista para o campo do direito. Revista Opinião Jurídica, Fortaleza, v. 19, n. 32, p. 316-339, set./dez. 2021. 